(c) American Dairy Science Association, 2003.

\title{
Concentrations of Sialyloligosaccharides in Bovine Colostrum and Milk during the Prepartum and Early Lactation
}

\author{
T. Nakamura*, H. Kawase*, K. Kimura†, Y. Watanabe†, M. Ohtanił, \\ I. Arai*, and T. Urashima* \\ *Department of Bioresource Chemistry, Obihiro University of Agriculture and Veterinary Medicine, \\ Inada cho, Obihiro, Hokkaido, 080-8555, Japan \\ †YAKULT Central Institute for Microbiological Research, 1796 Yaho, Kunitachi, Tokyo, 186-8650, Japan \\ ¥Field Center of Animal Science and Agriculture, Obihiro University of Agriculture and Veterinary Medicine, \\ Inada cho, Obihiro, Hokkaido, 080-8555, Japan
}

\begin{abstract}
Sialyloligosaccharides and sialylglycoconjugates in colostrum and milk are regarded to be important biological components with respect to be source of brain gangliosides in infant and to be antiinfectional components for the attack by the pathogenic bacteria and virus. Several acidic oligosaccharides have been characterised in both bovine and human milk or colostrum. The sialyloligosaccharide content of human colostrum and milk has been extensively studied, whereas that of cows milk and colostrum has received less attention. In this study, the concentrations of three sialyloligosaccharides of bovine colostrum and milk were determined at various stages during the prepartum and the first $7 \mathrm{~d}$ postpartum. The concentration of 3 'SL (Neu $5 \mathrm{Ac}(\alpha 2-3) \mathrm{Gal}(\beta 1-$ 4)Glc) reached a maximum value of $0.85 \mathrm{mg} / \mathrm{ml}$ immediately following parturition while the concentrations of 6 'SL (Neu5Ac $(\alpha 2-6) \mathrm{Gal}(\beta 1-4) \mathrm{Glc})$ and 6 'SLN $(\mathrm{Neu} 5 \mathrm{Ac}(\alpha 2-6) \mathrm{Gal}(\beta 1-4) \mathrm{GlcNAc})$ of 0.14 and $0.12 \mathrm{mg} /$ $\mathrm{ml}$, respectively, were much lower at this initial stage, although these concentration were maximum immediately following parturition. Bovine colostrum, especially that collected immediately after parturition, may be suitable as a source of 3'SL and other sialyloligosaccharides for use as additives by the food or pharmaceutical industries.
\end{abstract}

(Key words: sialyloligosaccharides, pyridylamination, bovine, colostrum)

Abbreviation key: 3'SL $=\operatorname{Neu} 5 \operatorname{Ac}(\alpha 2-3) \operatorname{Gal}(\beta 1-4) G l c$, 6'SL $=$ Neu5Ac $(\alpha 2-6) \operatorname{Gal}(\beta 1-4)$ Glc,

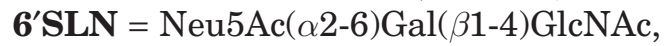
PA = pyridyl-2-amino.

Received May 20, 2002.

Accepted September 9, 2002.

Corresponding author: Tadashi Nakamura; E-mail address: nakamura@obihiro.ac.jp.

\section{INTRODUCTION}

Milk is a food for neonates that fulfills the nutritional requirements for their growth and development. Changes in the contents of its major components (i.e., fat, lactose, protein, etc.) during the course of lactation are well known in humans (Allen et al., 1991) as well as in domestic animals such as cows (Rook and Campling, 1965). The composition of colostrum differs from that of the mature milk; this difference is especially great in ruminants. Colostrum contains many kinds of biofunctional constituents, including growth factors, antipathogenic compounds and immune-enhancing components, as well as nutrients such as casein, lactose, fats, vitamins, and minerals. The biological role of colostrum has therefore been suggested to provide not only nutrients but also antiinfection factors against pathogenic bacteria and viruses for the newborn, whose immune system is not fully developed. Although the main focus has been on the immunoglobulins as the chief antiinfectional components in milk or colostrum, other antiinfectional factors have more recently been recognized to have significant roles in the protection of the young. These include proteins, such as lactoferrin and lysozyme, as well as free oligosaccharides or glycoconjugates acting as receptor analogues on gastrointestinal cell membranes.

Although the milk of most mammals contains lactose as the predominant carbohydrate, the milk or colostrum of many species also contains small amounts of free oligosaccharides, which usually have a lactose residue at their reducing ends. Bovine colostrum contains less free lactose but much higher concentrations of oligosaccharides and other glycoconjugates than the mature milk (Rook and Campling, 1965; Martin et al., 2001).

While the main significance of free lactose is as an energy source for the young, the sialyloligosaccharides and other sialylglycoconjugates are considered to be antiinfectional factors acting against rotavirus (Rolsma et al., 1998), rheovirus (Pacitti and Gentsch, 1987) and Helicobacter pylori (Simon et al., 1997). They also coun- 
Table 1. Contents of hexose and each sialyloligosaccharide in bovine milk before parturation.

\begin{tabular}{lllll}
\hline $\begin{array}{l}\text { Days before } \\
\text { parturition }\end{array}$ & $\begin{array}{l}\text { Hexose } \\
(\mathrm{mg} / \mathrm{ml})\end{array}$ & $\begin{array}{l}3^{\prime}-\mathrm{SL} \\
(\mathrm{mg} / \mathrm{ml})\end{array}$ & $\begin{array}{l}6^{\prime}-\mathrm{SL} \\
(\mathrm{mg} / \mathrm{ml})\end{array}$ & $\begin{array}{l}6^{\prime}-\mathrm{SLN} \\
(\mathrm{mg} / \mathrm{ml})\end{array}$ \\
\hline $0-2(\mathrm{n}=5)$ & $12.2 \pm 1.6$ & $0.717 \pm 0.027$ & $0.064 \pm 0.006$ & $0.100 \pm 0.007$ \\
$3-6(\mathrm{n}=4)$ & $6.0 \pm 1.4$ & $0.557 \pm 0.175$ & $0.052 \pm 0.010$ & $0.075 \pm 0.017$ \\
$7-10(\mathrm{n}=4)$ & $5.3 \pm 1.1$ & $0.262 \pm 0.076$ & $0.040 \pm 0.005$ & $0.074 \pm 0.004$ \\
$11-14(\mathrm{n}=4)$ & $2.7 \pm 1.4$ & $0.135 \pm 0.073$ & $0.018 \pm 0.010$ & $0.064 \pm 0.022$ \\
\hline
\end{tabular}

Values are means \pm SEM.

teract Vibrio cholera toxin (Schengrund et al., 1989) and promote the growth of bifidobacteria in the neonatal intestinal tract (Rueda et al., 1998). It has been reported that bovine colostrum contains several kinds of sialyloligosaccharides including $\operatorname{Neu} 5 \operatorname{Ac}(\alpha 2-3) \operatorname{Gal}(\beta 1-4) \mathrm{Glc}$ $\left(3^{\prime} \mathbf{S L}\right), \quad \operatorname{Neu} 5 \operatorname{Ac}(\alpha 2-6) \quad \operatorname{Gal}(\beta 1-4) \mathrm{Glc} \quad\left(\mathbf{6}^{\prime} \mathbf{S L}\right) \quad$ and Neu5Ac $(\alpha 2-6) \operatorname{Gal}(\beta 1-4)$ GlcNAc $\quad\left(6^{\prime}\right.$ SLN) (Parkkinen and Finne, 1987). However, there is a lack of detailed knowledge of the concentrations of sialyloligosaccharides in bovine colostrum. This paper describes the results of the determination of the concentrations of sialic acid and of these sialyloligosaccharides in bovine colostrum and milk during the early stages of lactation.

\section{MATERIALS AND METHODS}

\section{Materials}

The samples of colostrum and postpartum milk were obtained from four individual Holstein cows reared in the farm of Obihiro University of Agriculture and Veterinary Medicine. Cows, which calved from two to four times, were fed approximately 50\% hay and 50\% standard concentrate. Calving took place in July and August. The prepartum milk was collected from 17 cows at various times (from 0 to $14 \mathrm{~d}$ ) prior to parturition (see Table 1). The samples of colostrum and postpartum milk were collected immediately after parturition and then at $6,12,18$ and $24 \mathrm{~h}$, after which collections were done every $12 \mathrm{~h}$ up to $168 \mathrm{~h}(7 \mathrm{~d})$ postpartum. The sample volumes varied from about $4 \mathrm{~L}$ immediately after parturition to about $20 \mathrm{~L} 7 \mathrm{~d}$ postpartum. A 10 $\mathrm{ml}$ aliquot of each of the milk samples was frozen immediately after collection and then stored at $-20^{\circ} \mathrm{C}$ until analysis. Authentic 3'SL, 6'SL and 6'SLN were purchased from Dextra Laboratories Ltd. (Reading, U.K.).

\section{Methods}

Hexose and sialic acid in whole milk. Following appropriate dilution of the milk samples with distilled water, the milk hexose content was determined by the phenol sulfuric acid method (Dubois et al., 1956) using lactose as the standard (Marier and Boulet, 1959). The sialic acid content was determined by the periodic acid- resorcinol method (Svennerholm, 1957) using N-acetylneuraminic acid as the standard.

Preparation of the crude sialyloligosaccharides fraction. A $1 \mathrm{ml}$ aliquot of each milk sample was warmed to $40^{\circ} \mathrm{C}$ and thoroughly mixed with 4 volumes of chloroform/methanol $(2 / 1, \mathrm{v} / \mathrm{v})$. After centrifugation at $2500 \mathrm{rpm}$ for $30 \mathrm{~min}$ the methanol/water layer in the upper phase was concentrated by evaporation to remove the methanol, which was followed by lyophilization. The lyophilized material was dissolved in $1 \mathrm{ml}$ of distilled water and applied to a Dowex 1X2 anion exchange column (acetate form), $1.5 \times 6.0 \mathrm{~cm}$ (Dow Chemical Company, MI). Elution was done first with $50 \mathrm{ml}$ of water (wash) and then with $50 \mathrm{ml}$ of $1 M \mathrm{NaCl}$ solution and $5 \mathrm{ml}$ fractions were collected. The hexose and sialic acid contents in an aliquot of each fraction were monitored by the phenol- $\mathrm{H}_{2} \mathrm{SO}_{4}$ and the periodic acid-resorcinol method, respectively. Fractions which contained both hexose and sialic acid were pooled and desalted by electrodialysis using a MICRO ACYLYZER model S-1 (Asahi Kasei Co., Kanagawa, Japan) with a 220-10 cartridge, followed by lyophilization.

Quantification of the sialyloligosaccharides. The pyridylamino (PA) derivatives of the sialyloligosaccharide fractions were prepared according to the method of Hase et al. (1994) modified by Kimura et al. (1995), as described below. The coupling reagent contained $552 \mu \mathrm{g}$ of 2 -aminopyridine (Wako Pure Chemical Industries Ltd, Osaka, Japan) dissolved in $200 \mu \mathrm{l}$ of acetic acid (Wako Pure Chemical Industries Ltd, Osaka, Japan). Of this reagent, $100 \mu \mathrm{l}$ were added to the sialyloligosaccharide-containing fraction lyophilized in a glass tube $(13 \times 100 \mathrm{~mm})$. The tube was sealed with a screw cap and heated at $90^{\circ} \mathrm{C}$ for $1 \mathrm{~h}$, after which 100 $\mu \mathrm{l}$ of the reducing reagent, which contained $200 \mathrm{mg}$ of Borane-dimethylamine complex (Aldrich Chemical Company Inc., USA) dissolved in $80 \mu \mathrm{l}$ of acetic acid, were added. The tube was resealed and heated at $80^{\circ} \mathrm{C}$ for $50 \mathrm{~min}$. The resulting PA derivatives were separated from the reaction mixture by electrodialysis using a MICRO ACYLYZER model S-1 (Asahi Kasei Co., Kanagawa, Japan), with a 220-10 cartridge, followed by lyophilization. 
The PA sialyloligosaccharide fractions were each dissolved in $1 \mathrm{ml}$ of distilled water and filtered through a DISMIC-13CP cellulose acetate membrane $(0.45 \mu \mathrm{m}$, Advantec Toyo, Tokyo). Aliquots of the filtrates were subjected to normal phase HPLC. The analysis was performed on a Tosoh CCPM-intelligent pump system (Tosoh Co., Tokyo) using a TSKgel Amido-80 column $(4.6 \times 250 \mathrm{~mm}$, pore size $80 \mathrm{~nm}$, particle size $5 \mu \mathrm{m}$, Tosoh Co., Tokyo, Japan). The mobile phase was 50 and $80 \%$ acetonitrile $\left(\mathrm{CH}_{3} \mathrm{CN}\right)$ in $15 \mathrm{mM}$ potassium phosphate buffer ( $\mathrm{pH}$ 5.2). Elution was done using a linear gradient of $\mathrm{CH} 3 \mathrm{CN}$ from 80 to $50 \%$ for $80 \mathrm{~min}$ at $40^{\circ} \mathrm{C}$ at a flow rate of $1 \mathrm{ml} / \mathrm{min}$. Detection was done with a MDPD-3600 multi-wavelength detector (Otsuka Electronics Co., Osaka, Japan) by monitoring the optical density of the eluate at $310 \mathrm{~nm}$. Identification was done by comparison of the retention time of each peak of the PA derivative with those of sialyloligosaccharide standards. Each sialyloligosaccharide in the fraction was quantified by calculating the ratio of its peak area to the peak areas of the standards.

\section{Statistical Analyses}

Statistical analyses were conducted using SAS. Results were expressed as means \pm SD.

\section{RESULTS}

Changes in the hexose and sialic acid content of the bovine colostrum and milk during the first $7 \mathrm{~d}$ of lactation are shown in Figure 1. The hexose content, which mainly originated from free lactose, was lowest (14 mg/ $\mathrm{ml}$ ) in the colostrum collected immediately after parturition. It markedly increased during the first $24 \mathrm{~h}$, reaching $42 \mathrm{mg} / \mathrm{ml}$ (which was similar to the hexose content of the mature milk) at $72 \mathrm{~h}$. The sialic acid content was $1.7 \mathrm{mg} / \mathrm{ml}$ in the colostrum collected immediately after parturition and then rapidly decreased, reaching $0.52 \mathrm{mg} / \mathrm{ml}$ at $24 \mathrm{~h}$; this was less than onethird of the intial sialic acid concentration. The sialic acid concentration then continued to decrease, reaching $0.15 \mathrm{mg} / \mathrm{ml}$ at $7 \mathrm{~d}$ postpartum.

Changes in the concentration of each of three individual sialyloligosaccharides, during the first $7 \mathrm{~d}$ postpartum, are shown in Figure 2. The 3'SL concentration was at a maximum value of $0.853 \pm 0.262 \mathrm{mg} / \mathrm{ml}$ immediately after parturition and rapidly decreased to 0.098 $\pm 0.010 \mathrm{mg} / \mathrm{ml}$ by $3 \mathrm{~d}$ postpartum. The concentrations of 6'SL and 6'SLN were both much lower than that of 3'SL during this stage of lactation. Their concentrations were also maximal at $0 \mathrm{hr}$ postpartum, being $0.141 \pm$ $0.062 \mathrm{mg} / \mathrm{ml}$ and $0.117 \pm 0.049 \mathrm{mg} / \mathrm{ml}$, respectively, after which they decreased to half of these maximum values by $24 \mathrm{~h}$ postpartum. a)

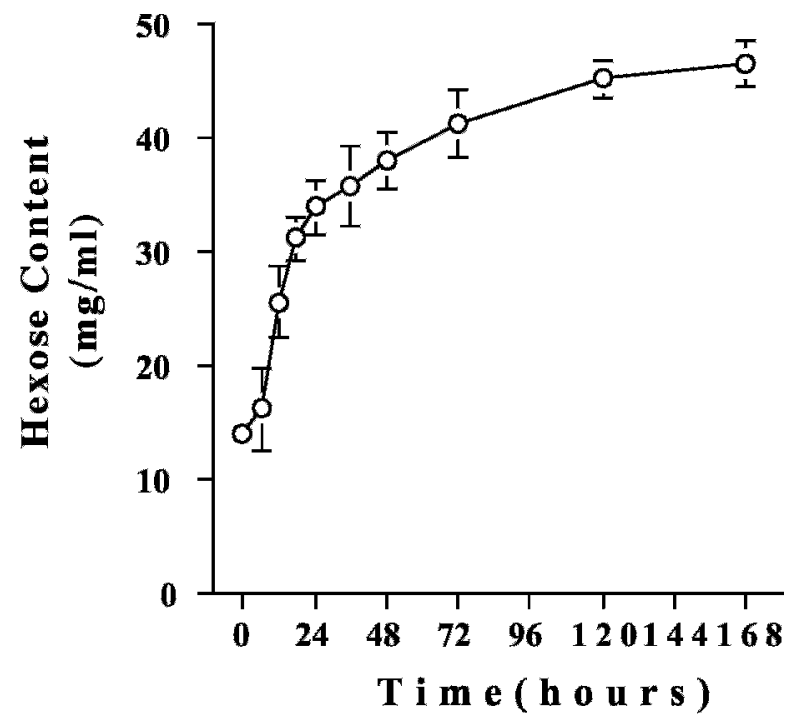

b)

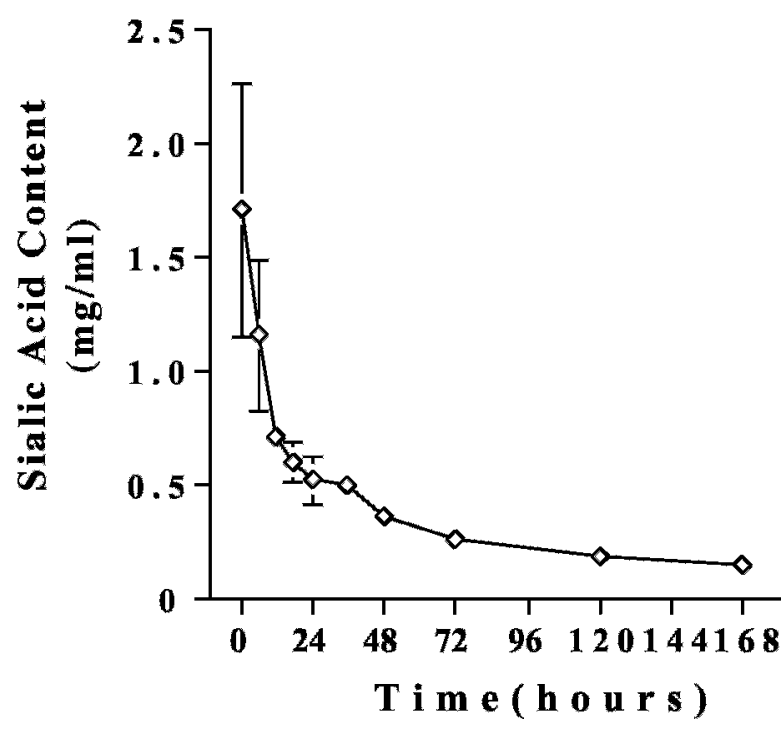

Figure 1. Changes in the hexose and sialic acid contents of bovine colostrum during early lactation. Values are indicated as means \pm $\mathrm{SD}(\mathrm{n}=4)$.

The concentrations of hexose and of each sialyloligosaccharide several days before parturition are shown in Table 1 . The hexose concentration was only $2.7 \mathrm{mg} /$ $\mathrm{ml} 11$ to $14 \mathrm{~d}$ before parturition but rose to $12 \mathrm{mg} / \mathrm{ml}$ 0 to $2 \mathrm{~d}$ prior to parturition. The concentration of each of the sialyloligosaccharides also rose until parturition, and became similar to the concentrations at 0 to $2 \mathrm{~d}$ prior to parturition.

\section{DISCUSSION}

Bovine milk contains lactose as the major carbohydrate, as is well known. The carbohydrate fraction is 

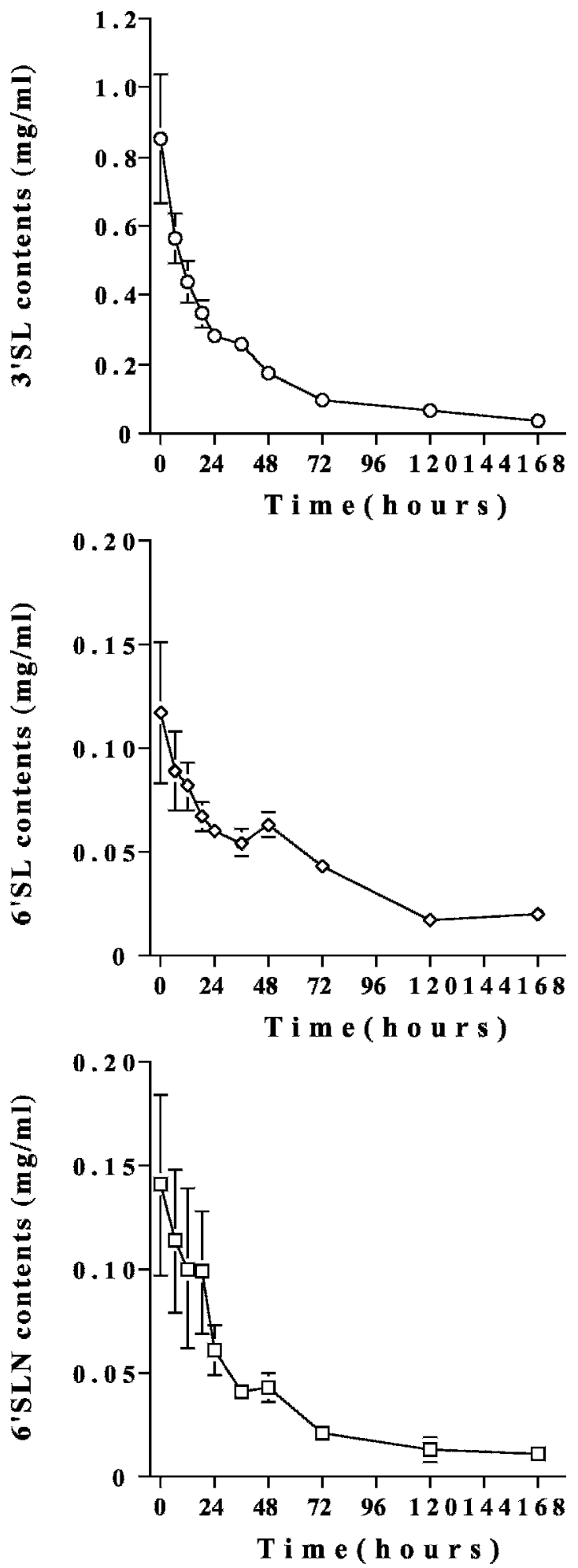

Figure 2. Changes in the concentrations of individual sialyloligosaccharides of bovine colostrum during early lactation. 3'SL, Neu5Ac( $\alpha 2-3)$ Gal( $\beta 1-4)$ Glc; 6'SL, Neu5Ac $(\alpha 2-6)$ Gal( $\beta 1-4) G l c ; 6$ 'SLN, $\operatorname{Neu} 5 \mathrm{Ac}(\alpha 2-6) \mathrm{Gal}(\beta 1-4) \mathrm{GlcNAc}$. Values are indicated as means $\pm \mathrm{SD}$ $(\mathrm{n}=4)$. composed of more than $95 \%$ of lactose and a few percent of other milk oligosaccharides including sialyloligosaccharides and carbohydrate moieties of glycoproteins or glycolipids. It can be assumed that the changes in hexose were caused mainly by changes in the lactose content. In our study, the value for hexose in the colostrum collected immediately after parturition was similar to the value for lactose of $20 \mathrm{mg} / \mathrm{ml}$ quoted by Rook and Camoling (1965).

Published data for sialic acid in bovine colostrum and milk differ considerably between various studies. Morrisey (1973) reported that the sialic acid content of early lactation bovine milk was $0.339 \mathrm{mg} / \mathrm{ml}$ while that of midlactation milk was $0.143 \mathrm{mg} / \mathrm{ml}$. Martin et al. (2001), however, reported that on the second day of lactation the sialic acid content was about $0.560 \mathrm{mg} /$ ml. On the other hand, Puente et al. (1992) reported that the sialic acid content rapidly decreased from 0.771 $\mathrm{mg} / \mathrm{ml}$ during the morning of the first day of lactation to $0.165 \mathrm{mg} / \mathrm{ml}$ on the third day. These values are within the sialic acid contents from 0 to $168 \mathrm{~h}$ postpartum reported in this study. Our results showed a similar pattern of decrease in the sialic acid content from 0 to $168 \mathrm{~h}$ postpartum, but our value immediately after parturition was somewhat higher $(0.853 \mathrm{mg} / \mathrm{ml})$ than that of Puente et al. (1992). Martin et al. and Puente et al. collected the colostrum and milk samples from Spanish-Brown cows. The small differences of the values of the contents among this study and theirs may be caused by the differences of the breeds. It is also suggested that they are caused by the differences of the quantitative methods.

This study provides first information about changes in the concentrations of individual sialyloligosaccharides in bovine colostrum and milk during early lactation. Veh et al. (1981), who isolated 3'SL, 6'SL and 6'SLN from cow's colostrum within $1 \mathrm{~h}$ postpartum, reported yields of $0.53 \mathrm{mg} / \mathrm{ml}, 0.065 \mathrm{mg} / \mathrm{ml}$ and 0.11 $\mathrm{mg} / \mathrm{ml}$, respectively. Our values for the concentrations of these oligosaccharides were somewhat higher than these, but it is possible that the differences were due to losses during the isolation of the sialyloligosaccharides by Veh et al. (1981). We determined each concentration of 3'SL, 6'SL and 6'SLN by HPLC analysis with their PA derivatives in the carbohydrate fractions in bovine colostrums and milk, but did not isolate each oligosaccharide. It is thought that the loss of the saccharides was smaller in our study than that of Veh et al. In this study, the concentrations of sialyloligosaccharides rapidly fell during the course of lactation until 2 to $3 \mathrm{~d}$ postpartum and were highest at $0 \mathrm{~h}$ postpartum, whereas the lactose concentration was lowest at that time. This indicates that the biosynthetic activity for the sialyloligosaccharides (i.e. sialyltransferase activ- 
ity) is highest at the beginning of lactation. It is therefore, likely that sialyloligosaccharides are more important for newborns than for older calves.

There are a number of studies that have suggested that sialylglycoconjugates have several biological functions for human and other mammalian infants. A part of the sialyloligosaccharides in rat milk are absorbed intact, or hydrolysed by sialidase and then absorbed as free sialic acid, from the small intestine of rat infants (Dickson and Messer, 1978; Witt et al., 1979). The free sialic acid may then be used as a material for the synthesis of rat brain gangliosides (Morgan and Winick, 1979,1980,1981; Witt et al., 1979; Carlson and House, 1986). Brain gangliosides are rapidly formed during the neonatal period. Mammals can generally synthesize sialic acid via $\mathrm{N}$-acetylmannosamine from fructose-6phosphoric acid and glutamic acid. However, in newborn rats the activity of UDP-N-acetylglucosamine 2'epimerase, which converts UDP-N-acetylglucosamine to N-acetylmannosamine, is low (Kikuchi et al., 1971). The neuraminidase activity of the intestinal mucosa of suckling rodents, rabbits and cats is higher than that of the adult animals (Dickson and Messer, 1978). It is likely, therefore, that some of the milk sialyloligoconjugates are a source of sialic acid for the newborns of these species. It is still unclear, however, whether this biological significance of milk sialyloligosaccharides is relevant to bovine newborns, which are much more highly developed at birth compared with neonatal rodents.

Nevertheless, it is known that, 3'SL, 6'SL and 6'SLN in milk are soluble receptor analogues for rotavirus, influenza virus A, B and Escherichia coli with S-fimbriae (Kawakami, 1974; Dai et al., 2000). E. coli is a pathogen which causes meningitis and septicemia in newborn infants. In fact, oral administration of N-glycolylneuraminic acid-containing ganglioside, which occurs in bovine colostrum, blood plasma and intestinal epithelium, has been shown to cure newborn calves infected with $E$. coli K99, a pathogen that causes diarrhea (Mouricot et al., 1990, Puente et al., 1992). These considerations suggest that the sialyl oligosaccharides in bovine colostrum protect the newborn against infection by these pathogenic microorganisms and bacterial toxins.

Rueda et al. (1998) observed that the addition of gangliosides to a milk formula, at the concentrations present in human milk, significantly modifies the fecal flora in preterm infants, with lower relative contents of $E$. coli and higher contents of bifidobacteria. Furthermore, Chierici et al. (1997) reported that a formula containing milk protein which had been desialylated by mild acid hydrolysis failed to induce a prevalence of colonization with bifidobacteria in 1-month-old infants, in contrast to breast-fed infants, $60 \%$ of which had detectable bifidus flora. This showed that sialylglycoconjugates in milk stimulate the colonization of the infant colon by bifidobacteria, most likely preventing the growth of pathogenic bacteria. The sialyloligosaccharides of bovine colostrum may have similar effects on newborn calves.

It is well known that the concentrations of milk constituents show considerable variation during the first week postpartum, especially during the first $48 \mathrm{~h}$. Bovine colostrum, $48 \mathrm{~h}$ after parturition, contains significant amounts of immunoglobulins (Rook and Campling, 1965; Porter and Conrad, 1967). These immunoglobulins are absorbed from the small intestine of newborn calves and enter the blood circulation, thus contributing to prophylaxis. Thus, the consumption of colostrum for 1 or $2 \mathrm{~d}$ postpartum enables the calves to receive passive immunity from their mothers. The pattern of a postpartum decrease in the immunoglobulin concentration of bovine milk is similar to that of the sialyloligosaccharides (Rook and Campling, 1965; Porter and Conrad, 1967). The rapid decrease in both the sialyloligosaccharide and the immunoglobulin concentrations cannot be explained only in terms of a change in the milk yield. The higher concentration of sialyloligosaccharides in bovine colostrum during early lactation may be related to prophylaxis against attacks by pathogenic bacteria and viruses, and also to the development of the colonic bifidus flora, prior to the calves acquiring their own immunity. Future studies involving the administration of sialyloligosaccharides to calves may help to clarify their detailed functions.

This study shows that bovine colostrum collected immediately after parturition is rich in 3 'SL, an oligosaccharide that has been shown to be a possible inhibitor of the actions of pathogenic microorganisms. Bovine colostrum, especially that collected immediately after parturition, may be suitable as a source of 3'SL and other sialyloligosaccharides to be used as additives in the food or pharmaceutical industries (Gopal and Gill, 2000).

\section{ACKNOWLEDGMENTS}

We thank Dr. M. Messer of the University of Sydney, Australia, for his invaluable suggestions and comments. This work was partially supported by a grantin-aid from Japan Council and by a grant-in-aid for science research (B) from Japan Society for the Promotion of Science.

\section{REFERENCES}

Allen, J. C., R. P. Keller, P. Archer, and M. C. Neville. 1991. Studies in human lactation: milk composition and dairy secretion rates 
of macronutrients in the first year of lactation. Am. J. Clin. Nutr. $54: 69-80$.

Carlson, S. E., and S. G. House. 1986. Oral and intraperitoneal administration of $\mathrm{N}$-acetylneuraminic acid: effect on rat cerebral and cerebellar N-acetylneuraminic acid. J. Nutr. 116:881-886.

Chierici, R., G. Sawatzki, S. Thurl, K. Tovar, and V. Vigi. 1997. Experimental milk formula with reduced protein content and desialylated milk proteins influence in the faecal flora and the growth of term newborn infants. Acta Paediatr. 86:557-563.

Dai, D., N. N. Nanthkumar, D. S. Newburg, and W. A. Walker. 2000. Role of oligosaccharides and glycoconjugates in intestinal host defense. J. Pediatr. Gastroenterol Nutr. 30 Suppl. 2:s22-s33.

Dickson, J. J., and M. Messer. 1978. Intestinal neuraminidase activity of suckling rats and other mammals. Relationship to the sialic acid content of milk. Biochem. J. 170:407-413.

Dubious, M., K. A. Gilles, J. K. Hamilton, P. A. Rebers, and F. Smith. 1956. Colorimetric method for determination of sugars and related substances. Anal. Chem. 28:350-356.

Gal, B., M. J. Ruano, R. Puente, L. A. Garcia-Pardo, R. Rueda, A. Gil, and P. Hueso. 1997. Developmental changes in UDP-N-acetylglucosamine 2-epimerase activity of rat and guinea-pig liver. Comp. Biochem. Physiol. B 118:13-15.

Gopal, P. K., and H. S. Gill. 2000. Oligosaccharides and glycoconjugates in bovine milk and colostrum. Br. J. Nutr. 84 Suppl. 1:S69-S74.

Hase, S. 1994. High-preformance liquid chromatography of Pridylaminated saccharides. Methods Enzymol. 230:225-237.

Kawakami, H. 1979. Biological significance of sialic acid-containing substances in milk and their application. Recent. Res. Devel. In Agriculture and Biological Chem. 1:193-208.

Kikuchi, K., H. Kikuchi, and S. Tsuiki. 1971. Activities of sialic acidsynthesizing enzymes in rat liver and rat and mouse tumors. Biochem. Biophys. Acta 252:357-368.

Kimura, K., K. Matsumoto, C. Ishihara, K. Harada, and A. Miyagi. 1995. Structure determination of galacto-oligosaccharids by pyridylamination and NMR spectroscopy. Carbohydr. Res. 270:33-42.

Marier, J. R., and M. Boulet. 1959. Direct analysis of lactose in milk and serum. J. Dairy Sci. 42:1390-1391.

Martin, M.-J., S. Martin-Sosa, L.-A. Garcia-Pardo, and P. Hueso. 2001. Distribution of bovine milk sialoglycoconjugates during lactation. 84:995-1000.

Morgan, B.L., J. Oppenheimer, and M. Winick. 1981. Effects of essential fatty acid deficiency during late gestation on brain $\mathrm{N}$-acetylneuraminic acid metabolism and behaviour in the progeny. Br. J. Nutr. 46:223-230.

Morgan, B. L., and M. Winick. 1981. The subcellular localization of administered $\mathrm{N}$-acetylneuraminic acid in the brains of well-fed and protein restricted rats. Br. J. Nutr. 46:231-238.

Morgan, B. L., B. L. Kuyatt, and J. Fink. 1985. Effects of hypothyroidism on the DNA, carbohydrate, soluble protein and sialic acid contents of rat submandibular glands. J. Oral Pathol. 14:37-41.
Morrisey, P. A. 1973. The N-acetylneuraminic acid content of the milk of various species. J. Dairy Res. 40:421-425.

Mouricout, M., J. M. Petit, J. R. Carias, and R. Julien. 1990. Glycoprotein glycans that inhibit adhesion of Escherichia coli mediated by K99 fimbriae: treatment of experimental colibacillosis. Infect. Immun. 58:98-106.

Pacitti, A. F., and J. R. Gentsch. 1987. Inhibition of reovirus type 3 binding to host cells by sialylated glycoproteins is mediated through the viral attachment protein. J. Virol. 61:1407-1415.

Parkkinen, J., and J. Finne. 1987. Isolation of sialyl oligosaccharides and sialyl oligosaccharide phosphates from bovine colostrum and human urine. Methods Enzymol. 138:289-300.

Porter, R. M., and H. R. Conrad. 1967. Postpartum changes in milk serum protein fractions. J. Dairy Sci. 50:505-508.

Puente, R., L.-A. Garcia-Pardo, and P. Hueso. 1992. Gangliosides in bovine milk. Changes in content and distribution of individual ganglioside levels during lactation. Biol. Chem. Hoppe-Seyler 373:283-288.

Rook, J. A. F., and R. C. Campling. 1965. Effect of stage and number lactation on the yield and composition cow's milk. J. Dairy Res. $32: 45-55$.

Rueda, R., J. L. Sabatel, J. Maldonado, J. A. Molina-Font, and A. Gil. 1998. Addition of gangliosides to an adapted milk formula modifies levels of fecal bEscherichia coli in preterm newborn infants. J. Pediatr. 133:90-94.

Rolsma, M. D., T. B. Kuhlenschmidt, H. B. Gelberg, and M. S. Kuhlenschmidt. 1998. Structure and function of a ganglioside receptor for porcine rotavirus. J. Virol.72: 9079-9091.

Rook, J. A. F., and R. C. Campling. 1965. Effect of stage and number of lactation on the yield and composition of cow's milk. J. Dairy Res. 32:45-55.

Schengrund, C. L., and N. J. Ringler. 1989. Binding of Vibrio cholera toxin and the heat-labile enterotoxin of Escherichia coli to GM1, derivatives of GM1, and nonlipid oligosaccharide polyvalent ligands. J. Biol. Chem. 264:18853.

Simon, P. M., P. L. Goode, A. Mobasseri, and D. Zopf. 1997. Inhibition of Helicobacter pylori binding to gastrointestinal epithelial cells by sialic acid-containing oligosaccharides. Infect. Immun. 65:750-757.

Svennerholm, L. 1957. Quantitative estimation of sialic acids: II. A colorimetric resorcinol hydrocholoric method. Biochim. Biophys. Acta 24: 604-611.

Veh, R. W., J. C. Michalski, A. P. Corfield, M. Sander-Wewer, D. Gies, and R. Schauer. 1981. New chromatographic system for the rapid analysis and preparation of colostrum sialyloligosaccharides. J. Chromatogr. 212:313-322.

Wang, B., J. C. Brand-Miller, P. McVeagh, and P. Petocz. 2001. Concentration and distribution of sialic acid in human milk and infant formula. Am. J. Clin. Nutr. 74:510-515.

Witt, W., H. von Nicolai, and F. Zilliken. 1979. Uptake and distribution of orally applied $\mathrm{N}$-acetyl-(14C)neuraminosyl-lactose and $\mathrm{N}$ acetyl-(14C)neuraminic acid in the organs of newborn rats. Nutr. Metab. 23:51-61. 